\title{
IMPROVEMENT OF STAR POSITIONS \\ BY A NEW AXIAL MERIDIAN CIRCLE \\ WITH NEGLIGIBLE SYSTEMATIC ERRORS
}

G.I. PINIGIN, A.V. SHULGA, P.N. FEDOROV, A.N. KOVALCHUK AND

A.E. MAZHAEV, A.G. PETROV, YU.I. PROTSYUK

Mykolayiv Astronomical Observatory

Observatorna, 1. Mykolayiv, 327030 Ukraine

Abstract. The Mykolayiv axial meridian circle (AMC) consists of a horisontal telescope with a pentagon prism of 'CITALL' in front of the objective of $D=180 \mathrm{~mm}$ and $F=2480 \mathrm{~mm}$ in the meridian, and a fixed aligned vacuum collimator of $D=180 \mathrm{~mm}$ and $\mathrm{F}=12360 \mathrm{~mm}$.

Investigations of the AMC parameters show that: horizontal flexure is negligible and about -0.037 "; collimation is stable and can be described by the formula $C=C^{\prime}+a \cdot t$, where $\mathrm{t}[\mathrm{C}]$ is the temperature, $\mathrm{a}=0.026^{\prime \prime}$ and $C^{\prime}$. const. The variation of collimator inclination is of the order 0.09 " per $1^{\circ} \mathrm{C}$. Test observations of FK5 stars show variations of the AMC intrumental system of not more than 0.1 ".

A CCD micrometer is being developed. Test observations with a pilot micrometer with a CCD of $288 \times 256$ pixels have started. It appears that the AMC magnitude limit (with cooling) will be about 14 and the positional accuracy 0.1 arcsec.

Finally, the expected capabilities of the fully automatic Mykolayiv AMC permit its efficient use for extention of the stellar reference frame to fainter magnitudes, for linking the optical/radio reference frames. In particular, for future observations a programme of $12-14^{m}$ reference stars around extragalactic radio sources is being prepared. 